\title{
Trayectos y Aconteceres: Estudios del Ser y el Quehacer del Maestro desde la Pedagogía
}

Trayectos y Aconteceres, emerge del grupo de investigación Violencia y Escuela que venía trabajando con proyectos financiados por el Centro de Investigaciones de la Universidad CIUP desde el año 2000. Durante este tiempo fue posible consolidar un equipo de trabajo que incluye docentes del departamento de Biología, maestros egresados del departamento, estudiantes adscritos a la línea, y maestros de diferentes colegios de la ciudad involucrados directamente con las investigaciones realizadas. En ese transcurrir, el objeto de investigación se ha ampliado y se ha transformado.

En el año 2005 el equipo se adentro en el estudio del embarazo adolescente. Durante esta indagación se realizaron varias discusiones alrededor del objeto de estudio del grupo y de su metodología, teniendo en cuenta que somos maestros interesados en hacer investigación desde la mirada que nos compete: la pedagogía. Estas discusiones, han posibilitado que el grupo se piense a sí mismo como equipo, realizando construcciones y decostrucciones de carácter teórico y metodológico que se visibilizan en su nuevo enfoque y en las nuevas propuestas de investigación.

Trayectos y Aconteceres: Estudios del ser y el quehacer del maestro desde la pedagogía, es el resultado de casi seis años de permanente reflexión enmarcada por ese "fantasma"1 que deambula por la Universidad y que nadie ha visto pero que está presente en nuestro ser y en nuestro quehacer: la pedagogía. La pedagogía entendida como saber, como el espacio relacional que posibilita movilizaciones, que va más allá de la estática de las disciplinas y de la explicación lineal de los objetos en la historia. Desde esta perspectiva hemos optado por asumir una mirada histórica a los acontecimientos, y la arqueología como caja de herramientas para la investigación, apartándonos de los estudios de caso y centrándonos en la emergencia de los hechos, las prácticas y las fuerzas de poder que sobre ellas se ejercen.

${ }^{1}$ Conferencia realizada por el profesor Carlos Noguera en VI Conversatorio sobre Violencia y Escuela: Hacia una formación docente dotada de sentidos. Bogotá, Mayo 27 de 2005. 
A partir de 2006, estamos trabajando sobre dos objetos de estudio: uno relacionado con la mirada hacia nosotros mismos indagando sobre la Enseñanza de la Biología en el Departamento de Biología de la Universidad Pedagógica Nacional, y otro, sobre la configuración y la historia de la sexualidad en la escuela, relacionada con lo encontrado en el proyecto sobre Madres Adolescentes Embarazadas llevado a cabo en el 2005.

Sobre la estructura, existe una coordinadora de Línea, una coordinadora de Práctica, y dos grupos de trabajo que responden a los objetos de estudio ya mencionados. Periódicamente realizamos reuniones de línea, básicamente con dos intenciones; la primera es conocer y discutir sobre los dos objetos de estudio, y la segunda la realización de seminarios académicos en aras de la actualización y el fortalecimiento de todas las personas de la Línea.

\section{Propósitos}

\section{General}

- Aportar a la construcción de un saber propio de la pedagogía desde la indagación histórica de las prácticas y los discursos sobre educación, enseñanza, aprendizaje, maestro, estudiante, escuela, saber pedagógico y disciplinas de enseñanza.

\section{Específicos}

-Establecer las condiciones de posibilidad de algunas prácticas y discursos relacionados con la pedagogía.

-Aproximarse a la comprensión de la pedagogía, desde la desarticulación permanente de los discursos y las prácticas que la atraviesan.

- Reflexionar sobre el ser y el quehacer del maestro desde la investigación pedagógica.

\section{Retos}

- Contribuir a hacer de la pedagogía el campo de saber del maestro.

- Rescatar al maestro como profesional, estudiando su ser y su quehacer desde el ámbito pedagógico.

- Fortalecer la practica pedagógica de los maestros en formación involucrando el trabajo investigativo en la constitución de su ser. 


\section{Investigaciones Realizadas por el Grupo.}

- Violencia y Escuela: Hacia la comprensión de sus manifestaciones e imaginarios presentes en la relación maestro - estudiante. Año 2000.

- Violencia y Escuela: Efectos de la práctica pedagógica en la generación, transformación y/o generación de violencia en la escuela. Año 2001 2002.

- Violencia y Escuela: Estudio de las rupturas significativas en el proceso de formación docente. Año 2003.

- Violencia y Escuela: Representaciones de adolescentes embarazadas y/o madres acerca del embarazo, del ser madres y de asumir la maternidad de instituciones educativas de Bogota. Año 2005.

- Trayectos y Aconteceres: Historia de las prácticas de enseñanza de la biología y la pedagogía en el departamento de biología de la universidad pedagógica nacional. Año 2006

- Trayectos y Aconteceres: Análisis de las prácticas discursivas acerca de la sexualidad en la escuela colombiana entre 1950 y 1960. Año 2006

- Trayectos y Aconteceres: Prácticas de normalización de las políticas educativas en la enseñanza de la biología y la pedagogía en el departamento de biología de la upn. Año 2006

- Trayectos y Aconteceres: Educación en Ciencias Naturales. Trayectos de una Historia en la UPN. Año 2007

- Trayectos y Aconteceres: La educación sexual en Colombia: análisis de los juegos de verdad en la escuela 1990-2007. Año: 2008

\section{Tesis:}

- OSORIO, Angélica; VALLEJO, Sonia. Universidad Pedagógica Nacional. Sinsentidos en la escuela: Aproximación a la comprensión de los sinsentidos de la escuela y su relación con la violencia en estudiantes de octavo y noveno del CED Don Bosco V. Departamento de Biología. 2004.

- ZIPAQUIRÀ, Liliana. Estudio de los mecanismos de sanción y su relación con la generación de violencia en la escuela. Caso: Liceo Social Compartir. Universidad Pedagógica Nacional. Departamento de Biología. 2002.

- ROA, Paola; SANABRIA, Robinson. Violencia simbólica en el discurso pedagógico de maestros. Caso: Liceo Social Compartir. "Los gestos y las palabras que duelen más que los golpes". Universidad Pedagógica Nacional. Departamento de Biología. 2002.

- ASCENCIO, Narda. Las actitudes de los estudiantes hacia el aprendizaje de la biología como un factor que incide en el proceso de construcción social de sentido. Universidad Pedagógica Nacional. Departamento de Biología. 2002. 
- RODRIGUEZ, Lizeth. Mujer, Sexualidad y Escuela: Imaginarios presentes en niñas pertenecientes a la Fraternidad Yo Soy la Puerta. Universidad Pedagógica Nacional. Departamento de Biología. 2000.

- RIVEROS, Olga Lucía. Caracterización y análisis de la relación entre maltrato infantil y aprendizaje en niñas de SantaFe de Bogotá, vinculadas a la asociación Fraternidad Yo Soy la Puerta. Universidad Pedagógica Nacional. Departamento de Biología. 1999.

- PUERTO, Mary Luz. Descripción e interpretación de las imágenes socio afectivas que construyen los alumnos de tercer grado con respecto a su maestra. Caso: Centro Educativo Distrital Rafael Pombo. Universidad Pedagógica Nacional. Departamento de Biología. 1999.

\section{Práctica Pedagógica.}

La línea de investigación se ubica en la mirada histórica de la pedagogía y desde la pedagogía, es decir, su labor no se centra en las Ciencias de la Educación tales como la psicología, la sociología, entre otras; sino más bien, en el maestro como actor principal de lo educativo, como sujeto que reflexiona, investiga, innova y crea, no solamente como persona que reproduce, mantiene y obedece. El acto educativo se constituye como el momento donde se crea conocimiento, un conocimiento escolar que es diferente al científico pero también al cotidiano; un saber propio de la escuela.

Se quiere hablar de la labor de los maestros, no solamente como "profesión", sino como forma de vida. Cada una de las personas que se involucran de manera responsable y consciente con la enseñanza, su oficio se les convierte en una forma de vivir; donde existe una participación activa en la formación de sujetos; sujetos que merecen la opción de pensar, escribir y reflexionar con un componente político fuerte, a partir de diferentes opciones de mirada, para que sea cada uno de ellos quien tome opciones y no sean otros los que lo hagan por ellos. Éste es el ser y el quehacer de una persona que se haga llamar MAESTRO.

Es así, que la práctica pedagógica se configura como la reflexión del sujeto maestro, que no se refiere exclusivamente a lo que se hace en el aula, o a la reproducción de las normas aprendidas culturalmente; sino más bien, que se constituye en la mirada de sí mismo, en el pensar lo que es y lo que hace. Esto se posibilita a través de la investigación como parte de la cotidianidad del maestro.

Por tanto la formación política y ética del maestro se configura como elemento fundamental de su ser y su quehacer; ya que asumimos al maestro más allá de un individuo que cumple con una obligación en el aula expositiva o demostrativa; lo pensamos como sujeto que es capaz de mirarse así mismo, de construir otras miradas, otros sentidos, de llegar a un cierto nivel de coherencia entre su discurso y su 
práctica, de problematizar su ser y su hacer; un sujeto, que está en la posibilidad de reconocer la existencia de otros, y que intencionadamente, posibilita que esos otros se miren así mismos mas allá de las categorías convencionales.

Frente a lo didáctico proponemos una indagación muy rigurosa frente a lo que se ha trabajado sobre didáctica de las ciencias en la Universidad. Esto se plantea porque también pensamos que a partir de una mirada histórica, podemos visibilizar qué se dice, qué se hace y cuáles son las discusiones actuales frente a la temática, ya que queremos interrogar el discurso manejado en Colombia, algunas veces desde el sentido común, sobre la didáctica.

\section{Publicaciones.}

Axolotl. (2004).Trayectos y aconteceres. Un proyecto sobre Violencia y Escuela. Centro de pedagogía y didáctica de la Biología, las Ciencias Naturales y la Educación Ambiental del Departamento de Biología. Universidad Pedagógica Nacional. Elaboración colectiva que da cuenta de los desarrollos académicos y teóricos que han realizado los miembros del equipo de investigación a lo largo de las diferentes etapas del proyecto.

Pinzón, J.E., Martínez, S., Rodríguez, L.; Riveros, O.L. (Julio de 2002). “Violencia y escuela: manifestaciones e imaginarios presentes en la relación maestro - estudiante". En: El oficio de Investigar. Educación y Pedagogía frente a nuevos retos. Universidad Pedagógica Nacional - CIUP.

"Sexualidad y escuela: posibles relaciones entre saber, poder y subjetividad en Colombia entre 1950 y 1960". IV congreso internacional sobre historia y prospectiva de las universidades de Europa y América y IV Seminario Nacional de Historia de la educación y la pedagogía Barquisimeto-Venezuela del 24 al 27 de octubre 2006.

Trayectos de maestro: de la búsqueda de sentido a la constitución de subjetividad. Encuentro Nacional de instituciones formadoras de formadores. Bogotá Colombia, 27 y 28 de octubre de 2006.

“Escuela y sexualidad: Educación y pedagogía en Colombia entre 1950 y 1960". Congreso Pedagogía 2007 encuentro por la unidad de los educadores la HabanaCuba del 29 de enero al 2 de febrero 2007.

\section{Eventos.}

- I Conversatorio sobre violencia y Escuela. Bogotá, Noviembre 2001 
- II Conversatorio sobre violencia y Escuela: Violencia en el aula. Bogotá, Mayo 9 de 2002

- III Conversatorio sobre violencia y Escuela: Los sentidos de la violencia desde el pensamiento sicoanalítico. Apuntes para la comprensión de la violencia escolar. Abril 25 de 2003.

- IV Conversatorio sobre violencia y Escuela: Cultura, educación y política: La Permanencia de la violencia en Colombia. Noviembre 7 de 2003.

- V Conversatorio sobre violencia y Escuela: Los sentidos de la otredad y la democracia en la escuela. Bogotá, Octubre 22 de 2004.

- VI Conversatorio sobre Violencia y Escuela: Hacia una formación docente dotada de sentidos. Bogotá, Mayo 27 de 2005.

- VII Conversatorio sobre Trayectos y Aconteceres: El ser y el que hacer del maestro. Bogotá, Octubre 7 de 2005.

- VIII Pensar la educación sexual: El embarazo adolescente en la escuela. Universidad Pedagógica Nacional. Bogotá. Septiembre 14 de 2007. 